
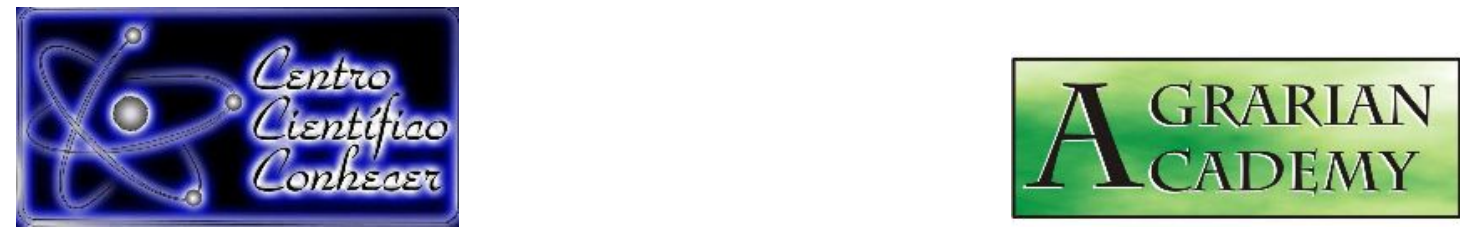

\title{
INVENTÁRIO E DIAGNÓSTICO DA ARBORIZAÇÃO DA PRAÇA REPÚBLICA DO IRAQUE EM BELO HORIZONTE, MG
}

\author{
Aderbal Gomes da Silva ${ }^{1}$, Glauciana da Mata Ataíde ${ }^{2}$
}

1, 2. Professor Doutor do Departamento de Engenharia Florestal da Universidade

Federal de São João del-Rei, Sete Lagoas-MG, Brasil. aderbalsilva@yahoo.com.br

Recebido em: 20/11/2019 - Aprovado em: 15/12/2019 - Publicado em: 30/12/2019

DOI: 10.18677/Agrarian_Academy_2019b6

\begin{abstract}
RESUMO
O objetivo deste trabalho foi realizar um inventário quali-quantitativo e o diagnóstico da arborização presente na Praça República do Iraque em Belo Horizonte, MG. Os parâmetros avaliados contemplam características gerais das espécies, do local e práticas de manejo. Identificou-se um total de 133 espécimes, distribuídos em 31 espécies e 15 famílias. Ocorreu uma predominância de espécies exóticas $(54, \%)$. A espécie de maior frequência foi Eucalyptus grandis (19,5\%). Quanto a condição fitossanitária obteve-se um percentual de $74,4 \%$ com fitossanidade boa, $11,3 \%$ regular, $14,3 \%$ ruim e nenhuma árvore morta. Em se tratando de manejo, 78,9\% dos indivíduos sem necessidade de poda; $10,5 \%$ poda para levantamento da copa, 9,0\% poda de limpeza e $1,5 \%$ poda de formação. A população arbórea inventariada apresentou boa qualidade fitossanitária e nenhum conflito com estruturas urbanas.
\end{abstract}

PALAVRAS-CHAVE: Praça, fitossanidade, qualidade de vida, vegetação urbana.

\section{INVENTORY AND DIAGNOSIS OF AFFORESTATION OF THE REPÚBLICA DO IRAQUE SQUARE IN BELO HORIZONTE, MG.}

\begin{abstract}
The objective of this work was to carry out a qualitative and quantitative inventory and the diagnosis of afforestation present in the Republic of Iraq Square in Belo Horizonte, MG. The evaluated parameters include general characteristics of the species, location and management practices. A total of 133 individuals were identified, distributed in 31 species and 15 families. There was a predominance of exotic species $(54, \%)$. The most frequent species was Eucalyptus grandis $(19.5 \%)$. Regarding the phytosanitary condition, $74.4 \%$ of the individuals classified in the class called good, $11.3 \%$ satisfactory, $14.3 \%$ poor and no dead tree were obtained. In terms of management, $78.9 \%$ of individuals without pruning; $10.5 \%$ canopy pruning, $9.0 \%$ cleaning pruning and $1.5 \%$ formation pruning. The inventoried tree population showed good phytosanitary quality and no conflict with urban structures.
\end{abstract}

KEYWORDS: Urban vegetation, square, plant health, quality of live. 


\section{INTRODUÇÃO}

Com o passar dos anos as comunidades urbanas têm convivido cada vez menos com a vegetação, isso se deve tanto a transformação do ambiente natural quanto do ambiente construído (EDSON-CHAVES et al., 2019). Com o desenvolvimento das cidades, é cada vez maior a preocupação com a qualidade de vida nos centros urbanos. Assim, a arborização ao longo das vias públicas e praças têm grande importância na estruturação da urbe, concorrendo na melhoria de aspectos sanitários, como por meio da retenção de poluentes atmosféricos e da atenuação da poluição sonora, bem como outros de cunho social e estético (SILVA et al., 2019).

Neste contexto, a vegetação urbana representa um elemento essencial para a recuperação do equilíbrio ambiental do meio urbano. A importância está diretamente ligada a melhoria da qualidade de vida da população, amenizando os efeitos artificiais desse ambiente (ZAMPRONI et. al., 2019). Assim a arborização pode ser considerada como um dos mais importantes elementos naturais que compõem o ecossistema urbano e que, devido aos seus benefícios deveria integrar qualquer planejamento urbano (OLIVEIRA et al., 2013).

Neste cenário, subsistem reduzidas áreas de vegetação, ou seja, fragmentos dos ambientes originais, os quais, mesmo segregados pela ação do homem, exercem grande função social, na maioria das vezes interligada a fatores como o microclima (MARTINI; BIONDI, 2015).

A praça como espaço público sempre teve um referencial urbano marcado pela convivência humana, servindo como um importante equipamento histórico cultural urbano que, especialmente no Brasil, expressa o surgimento e desenvolvimento de inúmeras cidades (ROMANI et al., 2012). As praças são espaços que podem abrigar massas vegetais significativas, que atuam diretamente na amenização microclimática, promovendo maior conforto ambiental e além disso, segundo Santos et al., (2017), favorece as interações sociais e melhora a qualidade de vida da população.

De acordo com Silva et al., (2019), para o usufruto dos benefícios proporcionados pelos espaços com cobertura vegetal, faz se necessário o entendimento da problemática decorrente da existência de características indesejáveis aos espécimes vegetais e da compatibilização do espaço com os equipamentos públicos. E também para que esse tipo de área verde possa ter os seus benefícios potencializados é necessário um planejamento criterioso, senão haverão mais conflitos do que benefícios. Segundo Bobrowski e Biondi (2016), o planejamento da arborização viária é um processo complexo que envolve aspectos ambientais, o desenvolvimento urbano e a preferência popular.

Assim, o planejamento da arborização viária e das praças públicas é fundamental para o desenvolvimento urbano, pois sem ele a expansão das cidades pode ocorrer de forma negativa, afetando diretamente a qualidade de vida dos cidadãos (KRAMER ; KRUPEK, 2012).

A maioria das cidades brasileiras não possuem dados qualiquantitativos da arborização de suas praças e áreas verdes. Segundo Silva e Silva (2012) a realização de inventários para conhecimento do patrimônio arbóreo e das principais necessidades de manejo, bem como a realização de avaliações periódicas, são de grande importância para a manutenção da qualidade destas áreas. 
$\mathrm{Na}$ cidade de Belo Horizonte a vegetação das praças contribui de forma significativa para o total de área verde pública, mas a maioria deste patrimônio não é catalogada ou inventariada. Assim, o levantamento dessa vegetação torna-se primordial para servir de suporte ao planejamento e tomadas de decisão relativas ao manejo destas áreas.

Então se propõe realizar um inventário quali-quantitativo e o diagnóstico das espécies arbóreas e arbustivas presentes na Praça república do Iraque no bairro Sagrada Família em Belo Horizonte, MG.

\section{MATERIAL E MÉTODOS}

O estudo foi realizado na Praça República do Iraque no bairro Sagrada Família na cidade de Belo Horizonte, MG, cujas coordenadas geográficas são: $19^{\circ}$ $55^{\prime}$ de latitude Sul e a $43^{\circ} 56^{\prime}$ de longitude Oeste. A altitude aproximada é de $875 \mathrm{~m}$ (Prefeitura Municipal de Belo Horizonte - PBH, 2019).

De acordo com a Köppen e Geiger a classificação do clima é Cwa, com temperatura média anual de $20,5{ }^{\circ} \mathrm{C}$ e $1430 \mathrm{~mm}$ de pluviosidade média anual (CLIMATE-DATA, 2019).

Realizou-se um levantamento completo ou censo, coletando dados quantitativos e qualitativos dos indivíduos arbóreos e arbustivos da Praça República do Iraque, em Belo Horizonte, MG. As informações coletadas por meio do inventário seguiram as recomendações de Silva et al., (2017), adaptadas às condições deste trabalho (Quadro 1). Os parâmetros quantitativos foram mensurados integralmente e agrupados em classes posteriormente para efeito de discussão dos dados.

QUADRO 1. Variáveis utilizadas no inventário e o detalhamento de suas respectivas classes.

\begin{tabular}{|l|l|}
\hline Nome da variável & Classes da Variável \\
\hline Altura total & 1) $<5 \mathrm{~m} ; 2) 5,1-10 \mathrm{~m} ; 3) 10,1-15 \mathrm{~m} ; 4)>15 \mathrm{~m}$. \\
\hline Altura primeira bifurcação & 1) $<1,0 \mathrm{~m} ; 2) 1,0-1,5 \mathrm{~m} ; 3) 1,51-2,0 \mathrm{~m} ; 4)>2,0 \mathrm{~m}$. \\
\hline Diâmetro do tronco (Dap) & 1) $<15 \mathrm{~cm} ; 2) 15,1-30 \mathrm{~cm} ; 3) 30,1-45 \mathrm{~cm} ;>4) 45 \mathrm{~cm}$. \\
\hline Fitossanidade & 1) boa; 2) regular; 3) ruim; 4) morta. \\
\hline Intervenção de poda & 1) ausente; 2) leve; 3) pesada; 4) drástica. \\
\hline Necessidade de poda & $\begin{array}{l}\text { 1) sem necessidade de poda; 2) poda de } \\
\text { levantamento de copa; 3) poda emergencial; 4) poda } \\
\text { de formação; 5) poda de limpeza; 6) poda para } \\
\text { liberação da iluminação. }\end{array}$ \\
\hline
\end{tabular}

A identificação das espécies botânicas inventariadas foi realizada por meio da observação de características dendrológicas em campo e da comparação com exsicatas do Herbário VIES da Universidade Federal do Espírito Santo (UFES).

Para o armazenamento e processamento dos dados foi utilizado o programa Microsoft Excel®. Para a análise e comparação dos resultados foi utilizada a estatística descritiva, por meio de gráficos e tabelas.

\section{RESULTADOS E DISCUSSÃO}

No inventário realizado na Praça República do Iraque no bairro Sagrada Família, foram identificados 133 indivíduos distribuídos em 31 espécies e 15 famílias. Destes 54,8\% pertencem a espécies exóticas (Tabela 1). 
TABELA 1 - Listagem florística das espécies inventariadas na arborização da Praça República do Iraque, contemplando a espécie, o nome vulgar, a família botânica, a origem, o número de Indivíduos (NI) e a Frequência relativa (FR).

\begin{tabular}{|c|c|c|c|c|c|}
\hline Nome científico & Nome popular & Familia botânica & Origem & N.I. & Fr\% \\
\hline Eucalyptus grandis & Eucalipto & Myrtaceae & Exótica & 26 & 19,5 \\
\hline Lagerstroemia speciosa & $\begin{array}{l}\text { Esculmilha-africana } \\
\text { Alecrim-de- }\end{array}$ & Lythraceae & Exótica & 17 & 12,8 \\
\hline Holocalyx balansae & campinas & Fabaceae & Nativa & 12 & 9,0 \\
\hline Clitoria fairchildiana & Sombreiro & Fabaceae & Nativa & 11 & 8,3 \\
\hline Terminalia catappa & Castanheira & Combretaceae & Exótica & 10 & 7,5 \\
\hline Pachira aquatica & Munguba & Malvaceae & Nativa & 5 & 3,8 \\
\hline Poincianella pluviosa & Sibipiruna & Fabaceae & Nativa & 5 & 3,8 \\
\hline Ceiba speciosa & Paineira & Malvaceae & Nativa & 4 & 3,0 \\
\hline Roystonea oleracea & Palmeira imperial & Arecaceae & Exótica & 4 & 3,0 \\
\hline Pinus sp. & Pinus & Pinaceae & Exótica & 4 & 3,0 \\
\hline Indeterminada (Indet.) & Indet. & Indet. & Indet. & 4 & 3,0 \\
\hline Jacaranda mimosifolia & Jacarandá-mimoso & Bignoniaceae & Exótica & 4 & 3,0 \\
\hline Dypsis lutescens & Areca-bambu & Arecaceae & Exótica & 3 & 2,3 \\
\hline Tipuana tipu & Tipuana & Fabaceae & Exótica & 3 & 2,3 \\
\hline Tibouchina granulosa & Quaresmeira & Melastomtacacea & Nativa & 2 & 1,5 \\
\hline Caryota urens & Palmeira-cariota & Arecaceae & Exótica & 2 & 1,5 \\
\hline Murraya paniculata & Murta & Rutaceae & Exótica & 2 & 1,5 \\
\hline Spathodea campanulata & Espatódea & Bignoniaceae & Exótica & 2 & 1,5 \\
\hline Paubrasilia echinata & Pau-brasil & Fabaceae & Nativa & 1 & 0,8 \\
\hline Cinnamomum zeylanicum & Canela-da-india & Lauraceae & Exótica & 1 & 0,8 \\
\hline Swietenia macrophylla & Mogno & Meliaceae & Nativa & 1 & 0,8 \\
\hline Cupresus sp. & Cipreste & Cupressaceae & Exótica & 1 & 0,8 \\
\hline Peltophorum dubium & Faveiro & Fabaceae & Nativa & 1 & 0,8 \\
\hline Tabebeuia roseoalba & Ipê-branco & Bignoniaceae & Nativa & 1 & 0,8 \\
\hline Handroanthus serratifolius & Ipê-amarelo & Bignoniaceae & Nativa & 1 & 0,8 \\
\hline Araucarea excelsa & Araucarea-excelsa & Araucariaceae & Exótica & 1 & 0,8 \\
\hline Vernonia polysphaera & Assa-peixe & Asteraceae & Nativa & 1 & 0,8 \\
\hline Cocus nucifera & Côco & Arecaceae & Exótica & 1 & 0,8 \\
\hline $\begin{array}{l}\text { Eucalyptus citriodora } \\
\text { Handroanthus }\end{array}$ & Eucalipto & Myrtaceae & Exótica & 1 & 0,8 \\
\hline pentaphyllus & Ipê-rosa & Bignoniaceae & Exótica & 1 & 0,8 \\
\hline Handroanthus & & & & & \\
\hline $\begin{array}{c}\text { chrysotrichus } \\
\text { Total geral }\end{array}$ & lpê-tabaco & Bignoniaceae & Nativa & $\begin{array}{c}1 \\
133\end{array}$ & $\begin{array}{c}0,8 \\
100,0 \\
\end{array}$ \\
\hline
\end{tabular}

As dez espécies de maior freqüência representaram $73,7 \%$ da população. A espécie Eucalyptus grandis foi a mais expressiva com um total de 26 espécimes inventariados, representando $19,5 \%$ dos indivíduos (Figura 1). Esse percentual é considerado elevado e encontra-se acima do recomendado (GREY; DENEKE, 1986), uma vez que o limite percentual máximo recomendado é de até $15,0 \%$, a fim de evitar problemas fitossanitários e a baixa diversidade pode potencializar o surgimento de pragas e doenças. Essa espécie normalmente não está entre as de maior arborização das cidades brasileiras, principalmente em áreas urbanas residenciais, sendo mais comumente encontrada às margens de rodovias compondo o paisagismo rodoviário. 


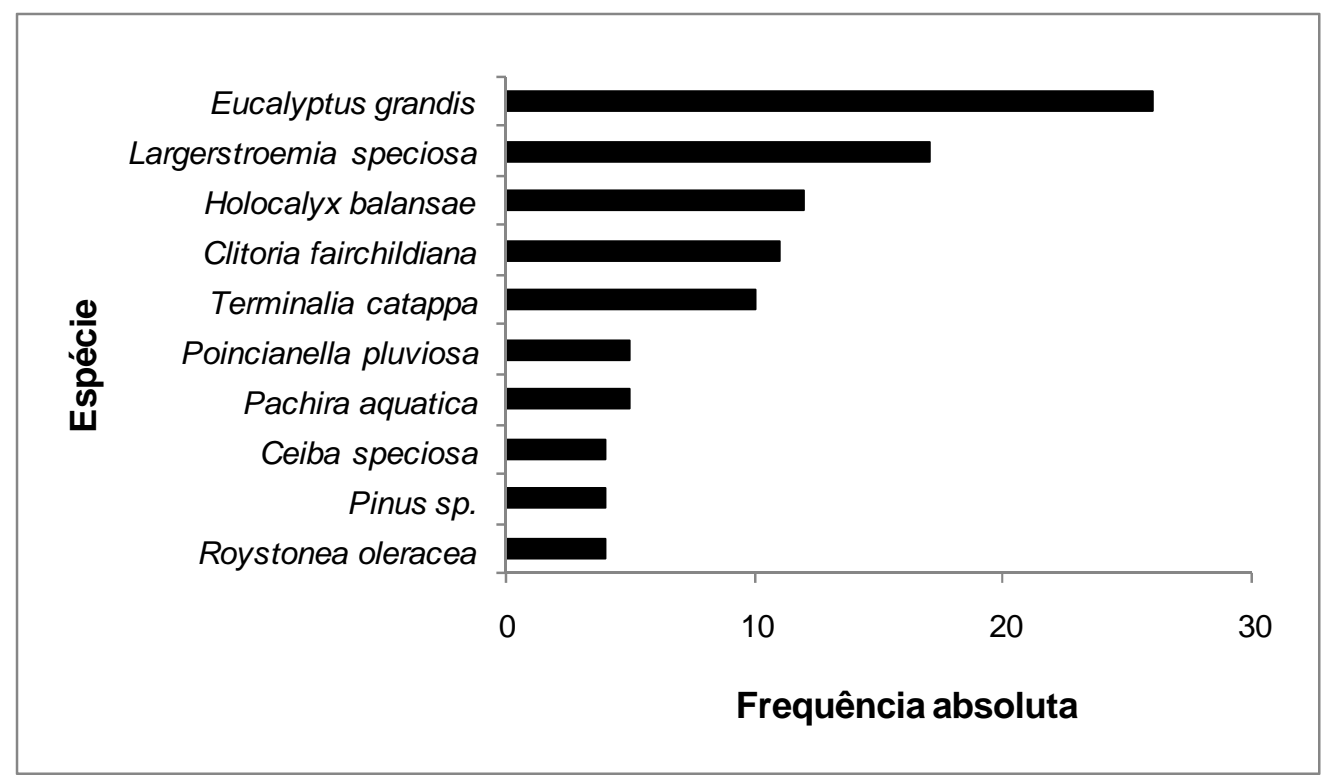

FIGURA 1. Freqüência das dez espécies mais representativas identificadas na Praça República do Iraque, no bairro Sagrada Família em Belo Horizonte, MG.

A Lagerstroemia speciosa foi a segunda espécie mais freqüente. Árvore caducifólia, porte variando de médio a grande, com tronco cilíndrico e casca finamente fissurada. É uma espécie muito comum na arborização da cidade de Belo Horizonte. Possui bela florada a qual pode apresentar tonalidades variadas como rosa claro, rosa escuro, lilás e violeta.

Quanto ao porte dos espécimes avaliados apresentaram altura média de 11,0 metros e diâmetro médio a altura do peito (DAP) de 28,7 centímetros. As classes hipsométricas e diamétricas estão ilustradas nas Figuras 2 e 3, respectivamente.

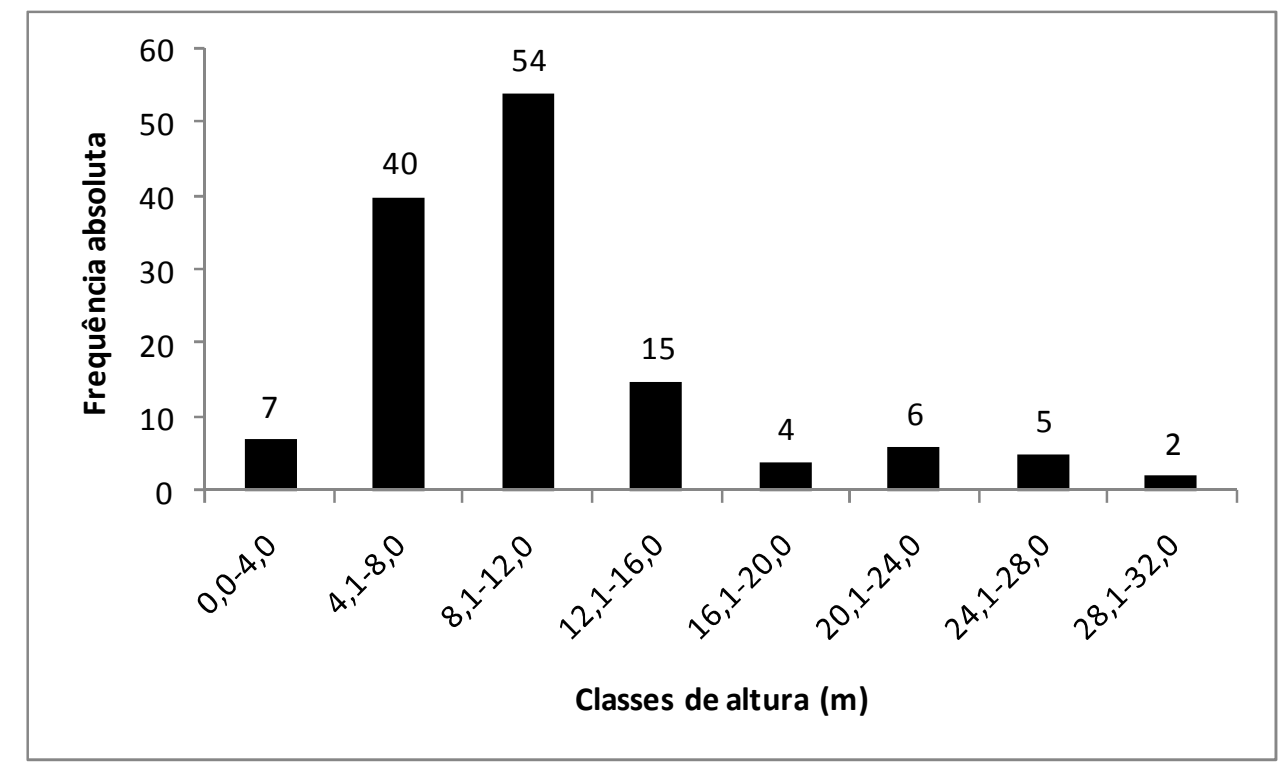

FIGURA 2. Distribuição das classes de altura dos indivíduos arbóreos presentes na Praça República do Iraque, localizada no bairro Sagrada Família em Belo Horizonte, MG. 


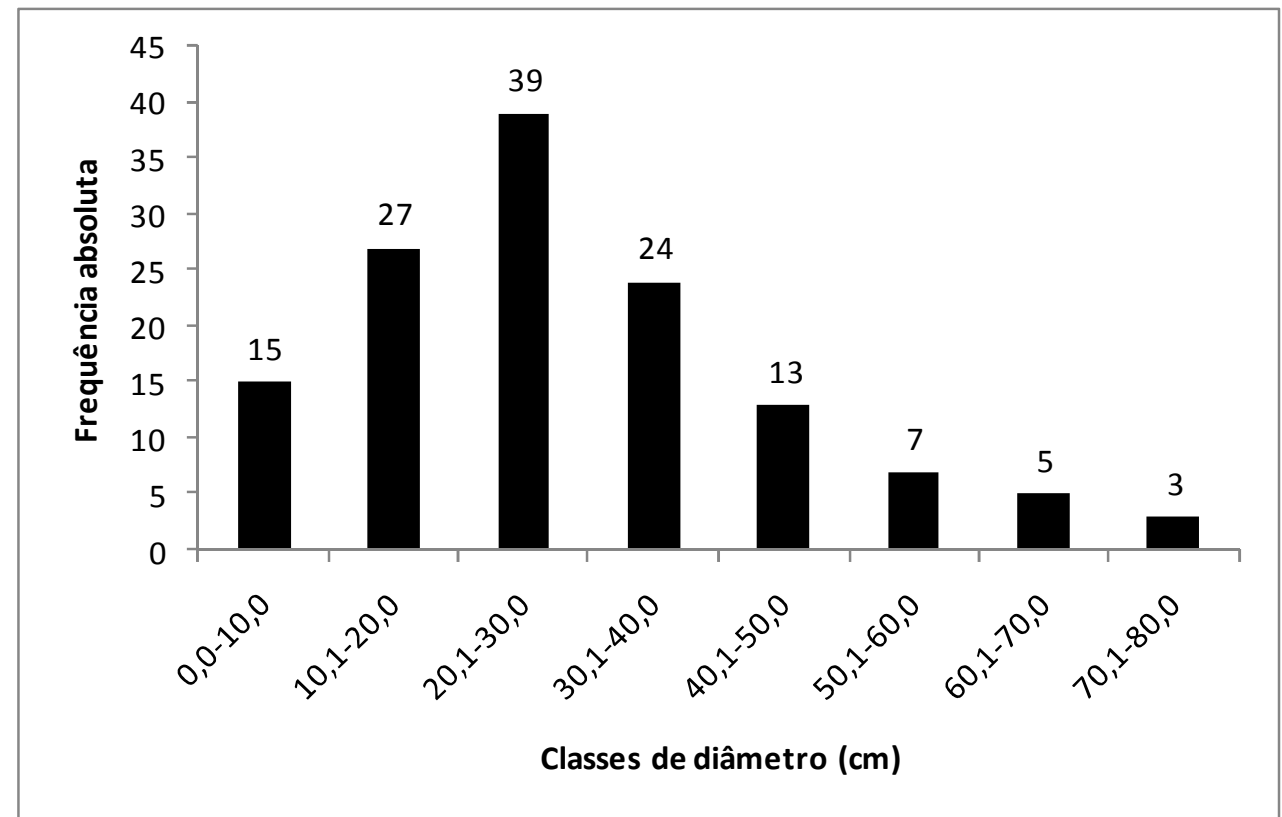

FIGURA 3. Distribuição das classes de diâmetro dos indivíduos arbóreos presentes na Praça República do Iraque, localizada no bairro Sagrada Família em Belo Horizonte, MG.

$\mathrm{Na}$ distribuição das classes de altura, observa-se que a maior freqüência foi na classe 8,1-12,0 m, caracterizada por indivíduos de médio e grande porte. Quanto às classes diamétricas a maior freqüência observada foi na classe de $20-30 \mathrm{~cm}$, também composta por indivíduos de médio e grande porte. A curva de distribuição dos diâmetros correspondeu à curva de distribuição unimodal. Esse tipo de distribuição a baixas taxas de novos plantios, indicando maior número de árvores adultas e poucos indivíduos jovens.

Quando tratamos do porte das árvores em arborização de cidades é importante analisar conjuntamente a distribuição hipsométrica e a diamétrica uma vez que a distribuição hipsométrica pode ser influenciada pela atividade de poda, principalmente as podas drásticas e podas de rebaixamento de copa.

Para a arborização de praças, como é o caso em questão, o problema da poda alterando a altura total não é comum, mas ainda podem ocorrem ações de manejo inadequadas rebaixando as copas das árvores, sendo recomendado sempre analisar conjuntamente altura total e diâmetro. Neste estudo aproximadamente $80 \%$ dos indivíduos presentes na praça não apresentaram necessidade de poda. Sendo assim, a redução da altura não representa uma preocupação (Figura 4).

Apenas $1,5 \%$ dos indivíduos necessitam de ajustes quanto à formação da copa, $10,5 \%$ de poda de levantamento de copa, por possuírem galhos pendentes interferindo na circulação de pedestres e 9,0\% poda de limpeza para remoção de galhos secos que podem comprometer a segurança. 


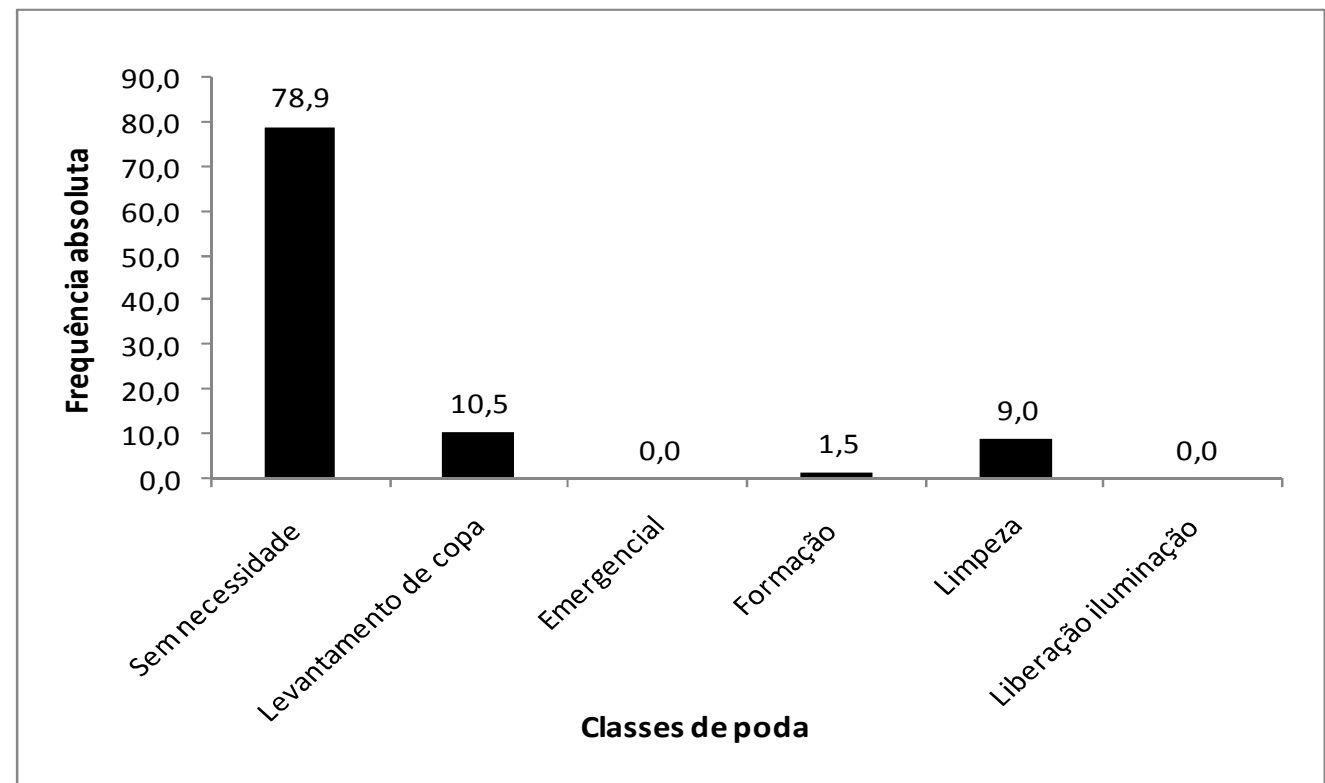

FIGURA 4. Classes de necessidade de poda para espécies arbóreas da Praça República do Iraque, localizada no bairro Sagrada Família em Belo Horizonte, MG.

Quanto a fitossanidade a maior parte da população arbórea apresenta-se em boa condição fitossanitária $(74,4 \%)$, que em se tratando de arborização de praças brasileiras esse valor pode ser considerado satisfatório, tendo em vista que essas árvores geralmente estão menos sujeitas a podas drásticas, o que geralmente compromete a qualidade fitossanitária (Figura 5). O percentual de espécimes deste estudo em boa condição fitossanitária se assemelha ao obtido por Silva e Silva (2012), para praças do bairro Floresta em Belo Horizonte, que foi de $78,3 \%$.

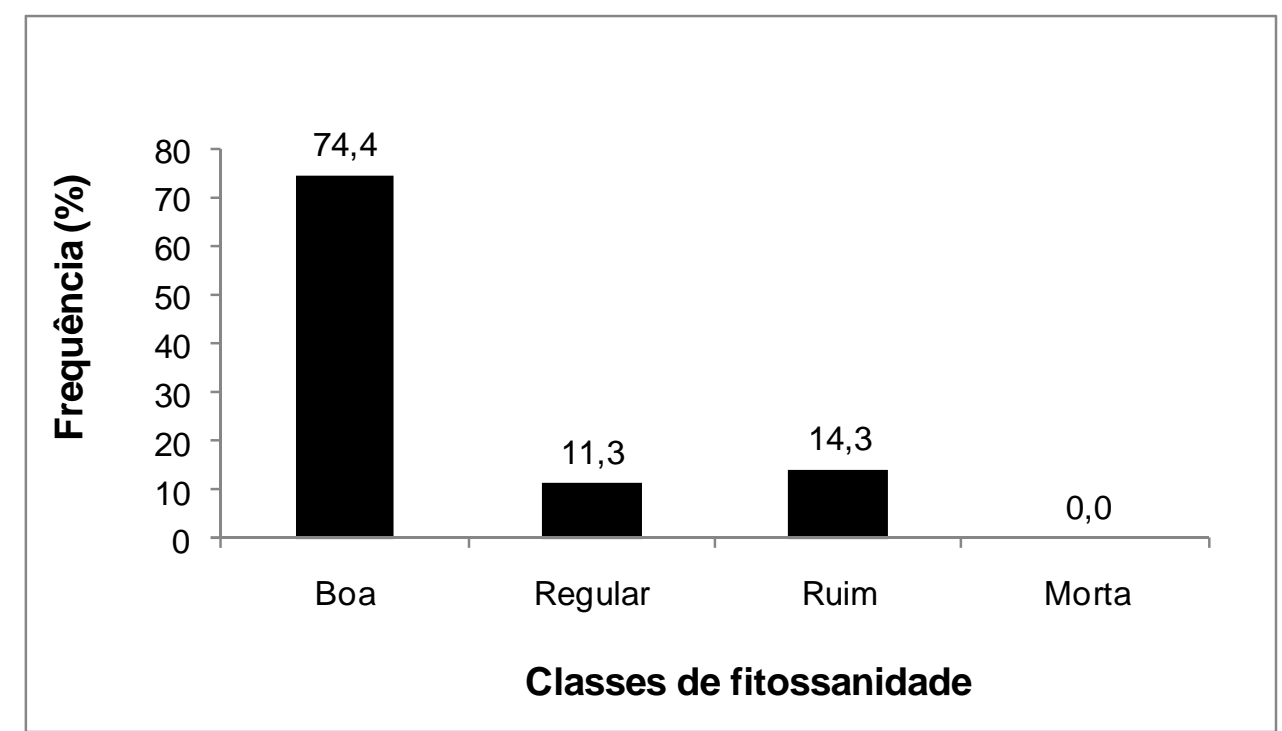

FIGURA 5. Freqüência das classes de fitossanidade dos espécimes arbóreos presentes na Praça República do Iraque, localizada no bairro Sagrada Família em Belo Horizonte, MG. 
Já em outras cidades brasileiras foram obtidos percentuais superiores para a categoria classificada como boa, tal como nos estudos realizados por Moreira et al. (2018), que registraram um percentual de 91,5\% de árvores em boas condições fitossanitárias na cidade e Planalto, BA. As árvores em condição classificada como ruim se deve a presença de danos mecânicos e/ou apodrecimento no tronco.

\section{CONCLUSÃO}

De modo geral a população inventariada apresenta uma diversidade satisfatória e boa qualidade fitossanitária.

A necessidade poda leve observada apenas para alguns indivíduos enfatiza a boa compatibilidade dos espécimes com o local.

A predominância de indivíduos de maior porte favorece a amenização microclimática, propiciando melhores condições de conforto térmico para a população.

Desta forma, se conclui que a arborização da praça avaliada desempenha adequadamente suas funções ecológicas, propiciando uma melhor qualidade de vida para os habitantes da região.

\section{REFERÊNCIAS}

BOBROWSKI, R. e BIONDI, D. Percepção e preferência popular por atributos estéticos e ecológicos na composição da arborização de ruas. Revista Floresta, Curitiba, PR, v. 46, n. 1, p. 123 - 133. 2016. Disponível em: DOl: 10.5380/rf.v46i1.43013

CLIMATE-DATA.ORG. Disponível em: https://pt.climate-data.org/america-dosul/brasil/minas-gerais/belo-horizonte-2889/\#climate-graph Acesso em: 02/06/2019.

EDSON-CHAVES, B.; DANTAS, A.G.B.; LIMA, N.S.; PANTOJA, L.D.M.;MENDES, R.M.S. Avaliação quali-quantitativa da arborização da sede dos municípios de Beberibe e Cascavel, Ceará, Brasil. Revista Ciência Florestal, Santa Maria, v. 29, n.1, p. 403-416, 2019.DOI: https://doi.org/10.5902/1980509829939.

GREY, G. W., DENEKE, F. J. Urban Forestry. New York, John Wiley \& Sons, 1986. $279 p$.

KRAMER J.A.; KRUPEK R.A. Caracterização florística e ecológica da arborização de praças públicas do município de Guarapuava, PR. Revista Árvore 2012; 36(4): 647658. http://dx.doi.org/10.1590/S0100-67622012000400007.

MARTINI, A.; BIONDI, D. Microclima e conforto térmico de um fragmento de floresta urbana em Curitiba, PR. Floresta e Ambiente, Rio de Janeiro, v. 22, n. 2, p. $182-$ 193, 2015. DOI: http://dx.doi.org/10.1590/2179-8087.082114

MOREIRA, G. L.; LIMA, M. C. D, ROCHA, M. B.; CUNHA, D. V. P.; FERRAZ, F. T. Diagnóstico quali-quantitativo da arborização de praças públicas na cidade de Planalto, BA. Agropecuária Científica no Semiárido, Patos-PB, v.14, n.2, p.168174, 2018. Disponível em: DOI: http://dx.doi.org/10.30969/acsa.v14i2.1019 
OLIVEIRA, A. S.; SANCHES, L.; MUSIS, C. R.; NOGUEIRA, M. C. J. A. Benefícios da arborização em praças urbanas - o caso de Cuiabá/MT. Revista Eletrônica em Gestão, Educação e Tecnologia Ambiental, v. 9, n. 9, p. 1900-1915, 2013. Disponível em: http://dx.doi.org/10.5902/223611707695.

PBH - PREFEITURA MUNICIPAL DE BELO HORIZONTE. https://prefeitura.pbh.gov.br/noticias/estudo-realiza-medicao-de-altitudes-em-belohorizonte. Acesso em 31/10/2019.

ROMANI, G.N., GIMENES, R., SILVA, M.T., PIVETTA, K.F.L., BATISTA, G.S. Análise quali-quantitativa da arborização na praça XV de novembro em Ribeirão Preto - SP, Brasil. Revista Árvore 2012; 36(3): 479-487. http://dx.doi.org/10.1590/ S0100-67622012000300010.

SANTOS, J. J. A.; SANTOS, A. E. S.; SILVA, A. M.; SANTOS, V. C.; SANTANA NETO, D. C. S. Levantamento botânico de plantas utilizadas na arborização urbana de Nova Palmeira, Paraíba. Revista Verde de Agroecologia e Desenvolvimento Sustentável, Pombal, PB, v. 12, n. 5, p. 866-873, 2017. DOI: http://dx.doi.org/10.18378/rvads.v12i5.5584.

SILVA, O.H.; LOCASTRO, J.K.; SANCHES, S.P.; ANGELIS NETO, G.; ANGELIS, B.L.D.; CAXAMBU, M.G. Avaliação da arborização viária da cidade de São Tomé, Paraná. Revista Ciência Florestal, Santa Maria, v. 29, n.1, p.371-384, 2019.DOI: https://doi.org/10.5902/1980509824889.

SILVA, A. G.; PAIVA, H. N.; GONÇALVES, W. Avaliando a Arborização Urbana. Viçosa, MG: Aprenda Fácil, 2ed., 2017. 296p. (Coleção Jardinagem e Paisagismo, Série Arborização Urbana, v. 5). (livro)

SILVA, A. G.; SILVA, A. G.. Inventário quali-quantitativo de espécies arbóreas e Arbustivas em praças do bairro Floresta na cidade de Belo Horizonte-MG. Enciclopédia Biosfera, Centro Científico Conhecer, Goiânia. v.8, N.14; p.1291 1298. 2012. http://www.conhecer.org.br/enciclop/2012a/ambientais/inventario.pdf

ZAMPRONI. K.; BIONDI, D.; BOBROWSKI, D. Avaliação quali-quantitativa da espécie Licania tomentosa (benth.) fritsch. na arborização viária de bonito-MS. Revista da Sociedade Brasileira de Arborização Urbana, Curitiba, PR, v.14, n.1, p. 42-52, 2019. DOI: http://dx.doi.org/10.5380/revsbau.v11i2.63421 